\title{
Semi Destructive Methods for Timber Structures Quality Assessment
}

\author{
Kristyna Vavrusova \\ VSB-Technical University Ostrava, Faculty of Civil \\ Engineering: Ostrava, Czech Republic \\ e-mail: kristyna.vavrusova@ vsb.cz
}

\begin{abstract}
- the content of this article is the assessment of the elements and truss structure state of the castle, which will soon be undergoing renovations. In addition to visual assessment was also used semi destructive drilling resistance measurement using rezistograph to determine the state of wood mass inside the cross-sections of individual elements, which allows to determine the real state of the elements beneath the surface, to determine the extent of infestation of individual elements of wood-destroying insects and decay and to determine the optimal process of reconstruction of the truss structure.
\end{abstract}

Keywords-semi destructive methods, timber, old-house borer, decay

\section{INTRODUCTION}

The Czech Republic located in the temperate zone is very rich in forests and the amount of structural wood, which is used for construction from everlasting.

Currently, there is a reconstruction of buildings mainly from the period of the 15-18 century (castles, parish or churches). In time of their implementation were not available impregnating agents for wood, especially against insects and rot.

A common problem is decay brought about by moisture, often owing to a leak, poor maintenance or condensation. This allows fungi or wood-boring insects to colonize the timber and by their action reduce its strength [1].

Construction of untreated wood roof trusses attacks mainly wood-destroying insects - old-house borer (Hylotrupes bajulus), which attacks mainly softwood such as spruce, pine and larch (see Fig. 1).

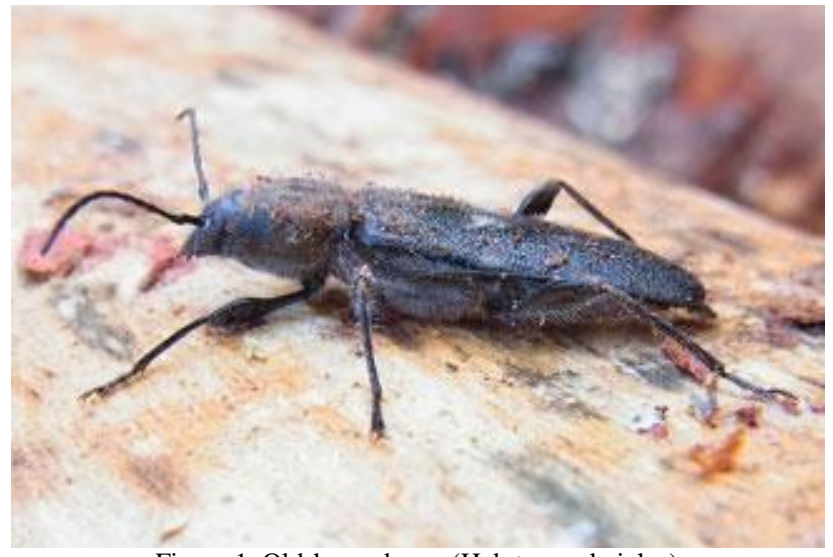

Figure 1. Old-house borer (Hylotrupes bajulus)

\author{
Libor Zidek \\ VSB-Technical University Ostrava, Faculty of Civil \\ Engineering: Ostrava, Czech Republi
}

The female lays eggs into the cracks of wood to a depth of about 20-30 mm. After 1-3 weeks hatch the larvae, starting eat timber (see Fig 2) [2 and 3].

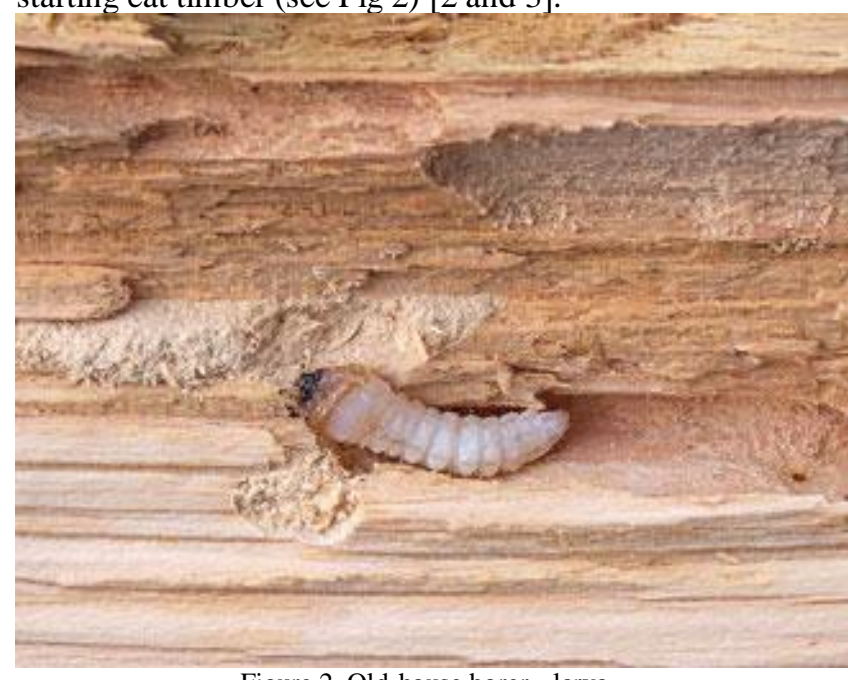

Figure 2. Old-house borer - larva

These larvae eat the wood inside the cross-section so the surface damage is not visible at first sight. Most of these buildings are currently historically protected and any destructive intervention into the structure when assessing its condition is prohibited.

To assess condition of the elements and the whole structure is possible only by using non-destructive methods - especially visual assessment, which is not fully conclusive, because of evaluation only superficial aspects.

The quality of wood inside the element for design of proper rehabilitation actions can be obtained through complementary semi destructive methods. One of them is resistograph testing.

The object of the exploration is the description of elements material quality of roof trusses over the object of castle (see Fig. 3) with a proposal for further progress of potential rehabilitations on the base of the gathered data. 


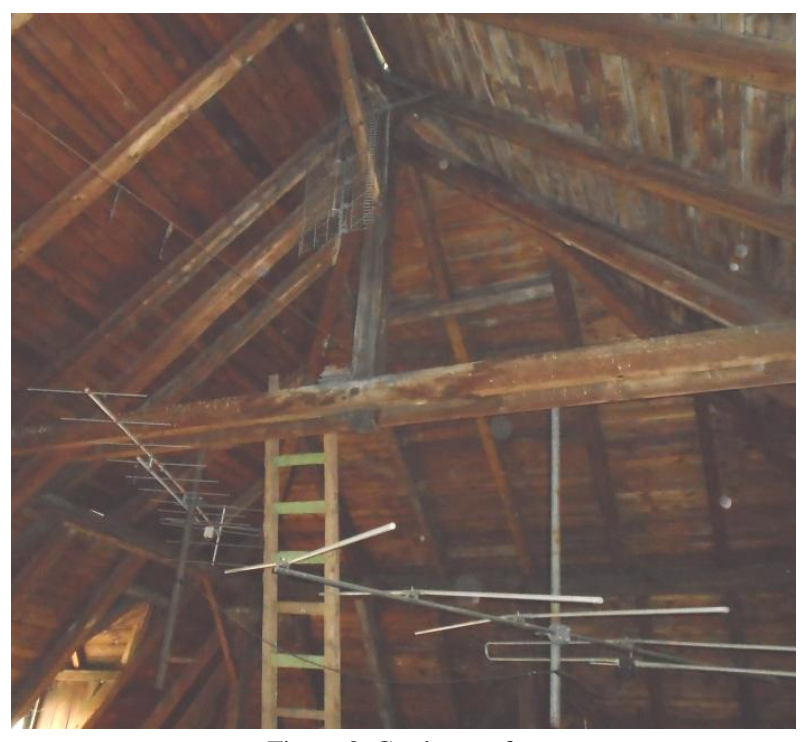

Figure 3. Castle- roof truss

II. METHODS AND SOLUTIONS

\section{A. Visual assessment}

Visual assessment is non-destructive method used to determine the quality or locate defects and failures of the element. On the beams attention is paid primarily to their placing in the ends, often due to bad implementation attacked by decay. Other aspects are presence of holes, indicate the potential infestation of the wood-destroying insects, drying cracks, rot away or fallen out knots and other factors that affect the quality of the investigated element [4].

\section{B. Drilling resistence measurement}

The drilling resistance method belongs to semi destructive methods and is suitable for identification of the internal damage of wood, such as created tunnels, cracks, decay and other internal changes in the structure of wood.

The healthy timber shows significantly higher values of drilling resistance (higher density profile) than the measured values for the damaged wood.

Measurements were performed using the apparatus Resistograph Resi PD 200 (see Fig. 4).

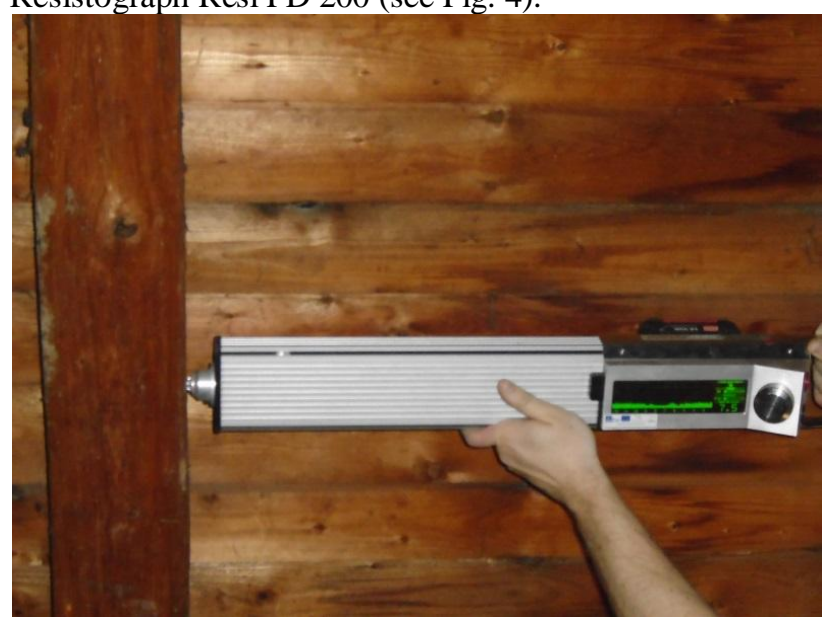

Figure 4. Resistograph Resi PD 200

\section{RESULTS}

Most of the elements of the assessed truss structure in the castle (vertical, horizontal and oblique) appear to be infested (old-house borer), whether locally or over the entire length.

The wood response to tapping for most of elements is hollow. In the vicinity of the elements is visible wooden powder (see Fig. 5).

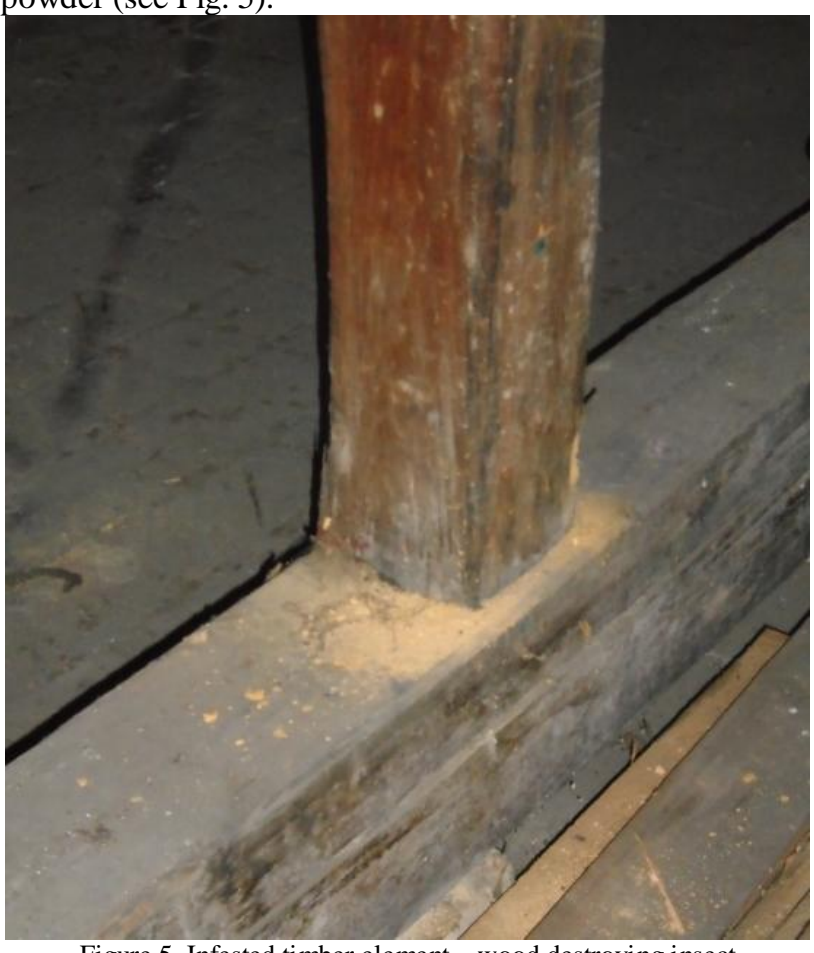

Figure 5. Infested timber element - wood destroying insect

For the measurement of the drilling resistance method was chosen always one element of the roof truss (freestanding column, the column by the wall, rafters, tie beam) and elements of visibly affected area by decay - the area of water leaking.

The first measurement was performed at the freestanding column, which is shown in Figure 5 - visibly infected with wood-destroying insects.

The center of the cross section shows greater resistance of the wood than its edge parts which are more affected by wood-destroying insects, which damages the timber progressively from the edges toward the middle of the cross-section (see Fig 6).

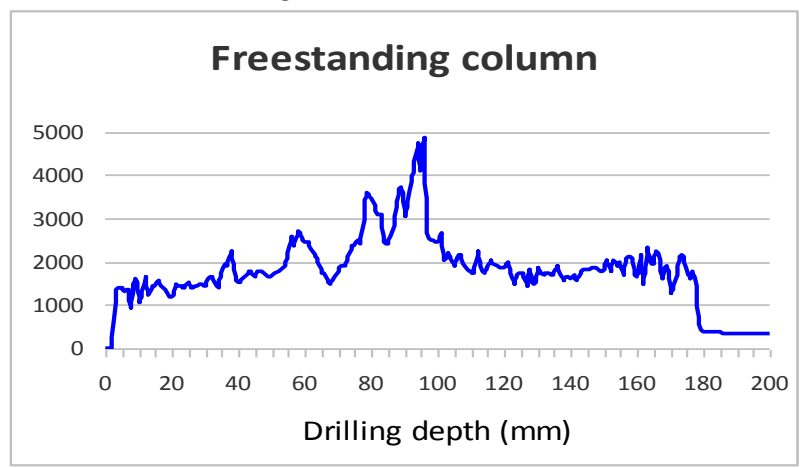

Figure 6. Drilling resistance - the freestanding column 
The second measurement was performed at the column standing by the wooden wall (see Figure 7). The result of the measurement shows significant decreases of wood practically the entire cross section of the column (see Figure 7).

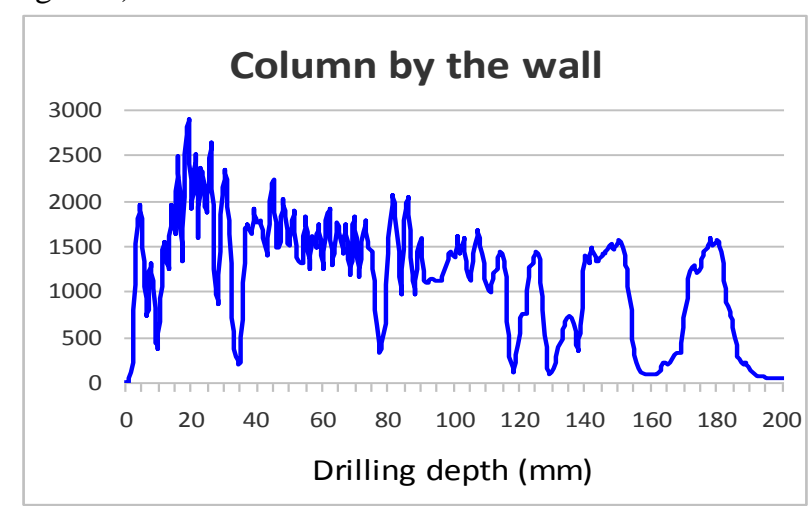

Figure 7. Drilling resistance - column by the wall

Another measurement was carried out on selected tie beam, which exhibited locally by wood-destroying insects (see Figure 8).

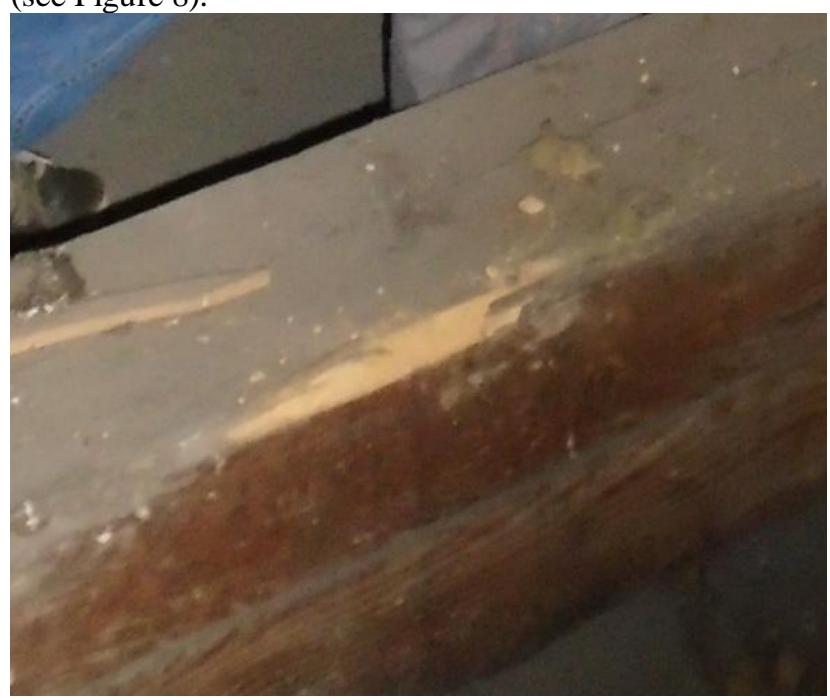

Figure 8 . Tie beam - wood-destroying insect damage

Measurement of the tie beam in the middle of its span does not show significant decreases in wood mass (Figure 9), although even this element is on its surface infected.

Tie beam in the middle of the span

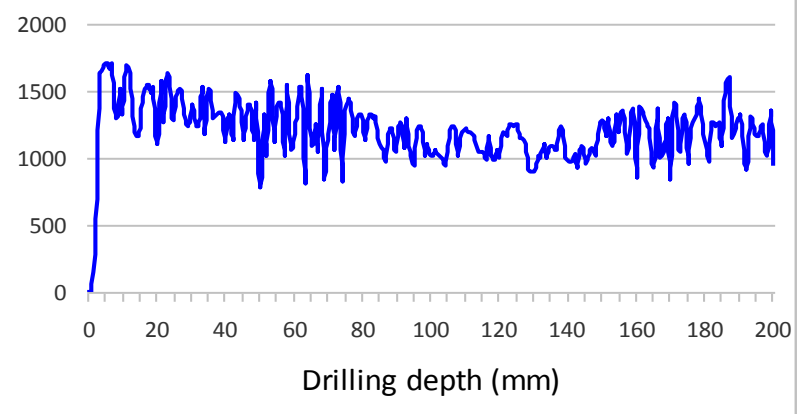

Figure 9. Drilling resistance - tie beam in the middle of the span

The results of drilling resistance measurements in the area of beam placing (see Figure 10) point to the damage wood mass with decay to the depth of $25 \mathrm{~mm}$. This is caused due to the increased moisture, which is caused by the lack of air circulation in this area.

\section{Tie beam in the area of placing}

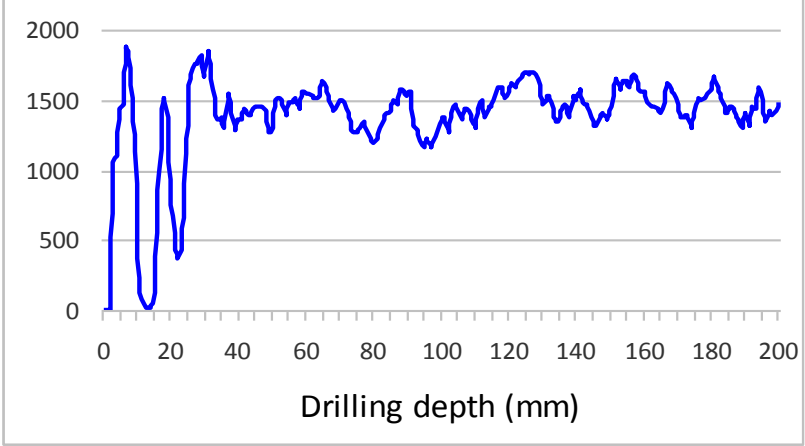

Figure 10. Drilling resistance - tie beam in the area of placing

In local areas, especially in places of tie beams placing and wall plates occurs due to low air circulation, and rainwater leaking wood infestation with decay. Locally in areas of water leaking there is a total destruction of wood mass.

In the area of the roof truss placing on the wall plate over which is the damaged roof deck constructions was locally excessive rainwater leaking onto the roof elements.

As can be seen in Figures 11 and 12 it is the complete loss and damage of wood mass in this area. The wood loses in this place consistency (firmness) and free falls off.

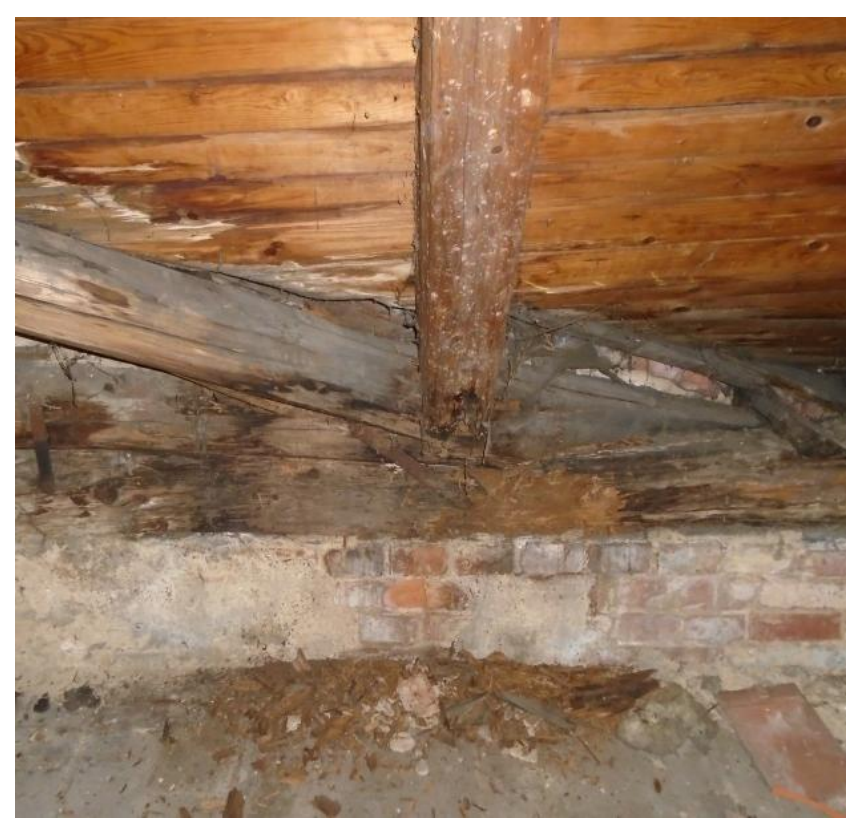

Figure 11. Water leaking area - damage of wood caused by decay 


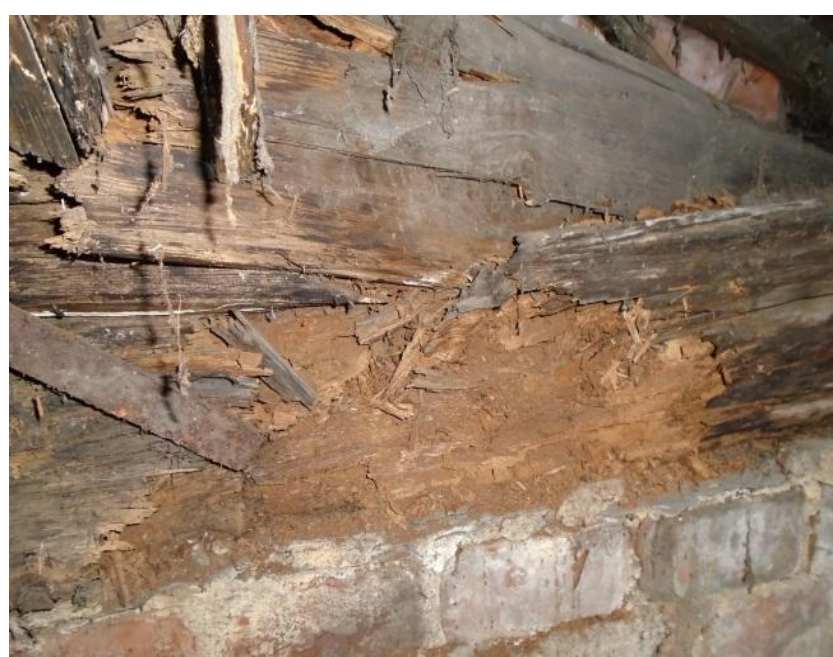

Figure 12. Water leaking area - damage of wood caused by decay detail

The results of the drilling resistance measurement of the damaged wall plate area has an almost zero resistance of timber (Figure 13) - it is the total destruction of the wood element, which confirms results of the visual inspection.

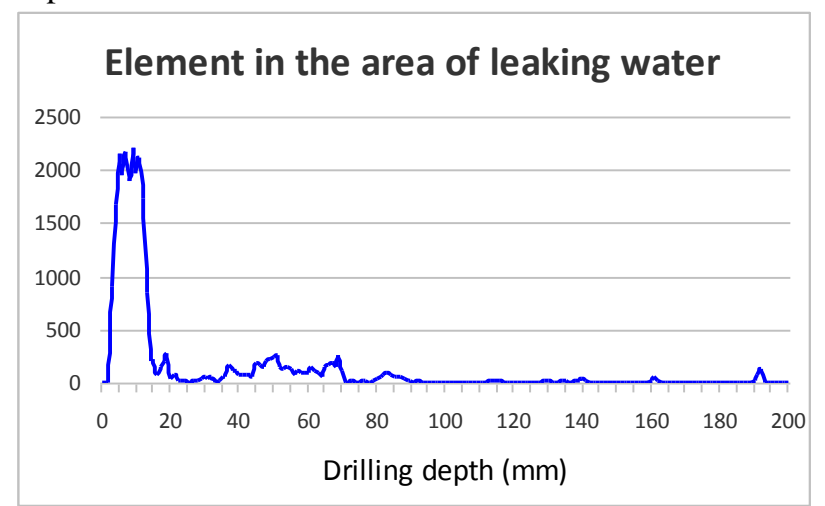

Figure 13. Drilling resistance - element in the area of water leaking

\section{CONCLUSIONS}

The visual assessment of elements is very quick and simple method to obtain basic information about the element under consideration - existence of insect holes and wooden powder demonstrates wood-destroying insect infestation, hollow element response to tapping and fallen off timber demonstrates decay infestation.

In structures where cannot be used destructive methods it is a suitable drilling resistance method, enabling easy and rapid determination of the actual extent of the infestation and of the state of wood mass inside the crosssections of the assessed element.

Based on the results of the visual assessment and drilling resistance method was due to a large extent of the wood-destroying insects and decay infestation of the roof truss, and the condition of the roof structure recommended the total replacement truss structure.

\section{ACKNOWLEDGEMENT}

This outcome has been achieved with funds of Conceptual development of science, research and innovation assigned to VŠB - Technical University of Ostrava by Ministry of Education Youth and Sports of the Czech Republic.

\section{REFERENCES}

[1] Nykanen, H. and Koricheva, J. 2004. Damage-induced changes in woody plants andtheir effects on insect herbivore performance: a meta-analysis. - Oikos 104: 247 - 268.

[2] Gadi VP Reddy. Fettkoher, R., Noldt, U., Dettner, K., Enhancement of attraction and trap catches of the old-house borer, Hylotrupes bajulus (CXoleoptera: Cerambycidae), by combination of male sey pheromone and monoterpenes, In Pest Management Science, Volume 61, 2005.

[3] Heijari, J., Nerg, A.M., Holopainen, J.K., Kainulainen, p., Wood borer performance and wood characteristics of drought-stressed Scots pine seedlings, In Entomologia Experimentalis et Applicata, Volume 137, 2010.

[4] CSN 73 2824-1 Strength grading of wood - Part 1: Coniferous sawn timber, 2015. 